\title{
En camino hacia Aparecida Un aporte centroamericano
}

\author{
Dean Brackley \\ Centro de Reflexión Teológica \\ San Salvador
}

Ofrezco las siguientes reflexiones como un pequeño aporte al proceso de preparación para la V Conferencia General del CELAM. Provienen de Centroamérica con las idiosincrasias y limitaciones correspondientes. Presentan la ventaja de que en el istmo centroamericano se manifiestan con intensidad los dolores y esperanzas de todo el continente, y de estos casos extremos con frecuencia se saca partido pedagógico. Por otra parte, en muchos aspectos Centroamérica se aparta de la norma continental. $\mathrm{Y}$ además, hay que tener en cuenta que estas reflexiones son selectivas y parciales.

Con todo, la realidad centroamericana plantea desafíos y oportunidades a la Iglesia que conviene compartir, más allá de sus fronteras, sin pretensión de abarcar todos los temas importantes, pero sí con la esperanza de profundizar la reflexión.

\section{Ver}

Comenzarnos repasando los signos de estos tiempos. Para identificarlos, no basta un análisis frío y científico, por mucho que esto pueda ayudar. Lo realmente indispensable es escuchar sus clamores con oldos de fe y ver la realidad con sensibilidad humana y cristiana. Se trata, sobre todo de percibir cómo se manifiesta en nuestra región el drama central de gracia y pecado, vida y muerte, esclavitud y libertad, amor y desprecio. Siguiendo a Puebla (nn. 31-39), partimos de los rostros humanos del Cristo, que sufre y espera en las victimas. Y añadamos que la verdad y la mentira son parte de la lucha del bien y del mal. Dentro en ese marco, esencialmente moral, hay que comprender el drama de la luz y las tinieblas. $Y$ dentro de este marco más amplio, hay que hacer también un diagnóstico de las crisis de sentido y del pluralismo religioso 
Los rostros. Cuarenta millones de personas viven en Guatemala, El Salvador, Honduras, Nicaragua, Costa Rica y Panamá. La mitad de esa población es rural - por el momento, ya que se urbaniza rápidamente'. Son países de grandes extremos, sociedades polarizadas, económica y políticamente (aunque en Panamá y Costa Rica hay ciertas excepciones, en ámbitos de polarización). Experimentan nuevas brechas generacionales y pluralismo religioso. Y también están polarizadas moralmente: azotadas por horribles injusticias y crueldades, pero son bendecidas a la vez por multitudes de creyentes generosos. Son pueblos crucificados que dan testimonio de vida eterna, en la vida diaria.

La pobreza es masiva. Como promedio, las personas reciben (es decir, consumen) menos de 2,000 dólares al año; en Honduras, menos de 1,000 y en Nicaragua, ni siquiera 500. Los gobiemos estiman -en realidad, subestiman la pobreza - que la mitad de la población es pobre, y que más del $20 \%$ sobrevive en la pobreza extrema. A excepción de Costa Rica, en un $60 \%$ de hogares no se satisface al menos una de las necesidades básicas (alimentación, vivienda, saneamiento, acceso a servicios de salud, educación, agua potable) $)^{2}$. De 1990 a 2003, la subnutrición en Centroamérica aumentó del 17 al 20, mientras en América Latina y El Caribe, en general, el porcentaje bajo, del 13 al 10\%, en el mismo período3.

La región "es una de las más desiguales del mundo"4. El 10\% de la población más rico, dependiendo del país, "se apropia de entre un $24.9 \%$ y un $40.5 \%$ del ingreso nacional", mientras que el $40 \%$ más pobre recibe entre un $10.4 \%$ y un $15.3 \%$. Los empleos son escasos y pobres. Faltan mecanismos distributivos. Casi la mitad de la población adulta - sobre todo la femenina y la rural - no ha terminado la escuela primaria, aunque ahora, las niñas asisten a la escuela más que antes ${ }^{5}$.

1. Programa de Naciones Unidas para el Desarrollo, Segundo informe sobre desarrollo humano en Censroamérica y Panamó (San José, 2003), p. 29. En adelante, me referiré a esta fuente como "PNUD CA". Para el presente ensayo, consideramos a Belice más como país caribeño que centroamericano.

2. PNUD CA, pp. 25, 29, 58-59. La mortalidad infantil en Costa Rica es 10.5 por mil nacidos, pero en Panamá llega hasta 21 , en El Salvador a 26; en Honduras a 32, en Nicaragua, a 36, y en Guatemala a 41 (ibid., p. 34).

3. Organización de Naciones Unidas para la Agricultura y la Alimentación (FAO), "Estrategia para extender a escala nacional el Programa Especial para la Seguridad Alimentaria -PESA- en América Central 2005-2009", p. 2. (http://www.fao.org/spfs/ pdf/Estrategia_PESACAM.pdf). En este período, "el número de personas afectadas por el hambre" en Centroamérica pasó de 4.9 a 7.4 millones. Ibíd. Cfr. idem, The State of Food Security in the World 2006, p. 19. (http://news.bbc.co.uk/1/shared/bsp/hi/ pdfs/30_10_06_fao.pdf)

4. Alexander Segovia, "Integración real y grupos centroamericanos de poder económico. Implicaciones para la democracia y el desarrollo regional", Estudios Centroamericanos 691-692 (2006) 532.

5. PNUD CA, pp. 30-31. 
En los últimos años, las presiones sociales han producido una desintegración social, en tres dimensiones: desmoronamiento de comunidades, de familias y de las mismas personas. Es fruto de la exclusión económica y social. Se vive una gran inseguridad económica y también física, sobre todo en las ciudades, debido a la delincuencia, las pandillas, el crimen organizado, la droga y la falta de un Estado de derecho. La corrupción permea la vida pública y privada. La violencia a veces supera los niveles alcanzados en las recientes guerras civiles.

La exclusión económica y la inseguridad generan una migración masiva. Cada día cientos de personas abandonan Honduras para Estados Unidos, y aún más abandonan El Salvador, diariamente. El $42 \%$ de la población salvadoreña dice que quiere emigrar. Se desgarran las familias, mientras las diásporas en "el norte" crecen a pasos agigantados. En Costa Rica viven 400,000 nicaragüenses. Los pueblos centroamericanos ya son binacionales, o trinacionales, y están implicados, permanentemente, en la realidad de Estados Unidos.

Una grave degradación ecológica se combina con la urbanización descontrolada y la vivienda precaria. Las enfermedades, las lluvias y los sismos se convierten en tragedias sociales. Empeñados en la apertura económica, los gobiemos han relegado el medio ambiente a un segundo plano?.

La economía. En los últimos quince años, en Centroamérica, como en el resto del hemisferio americano, se ha consolidado una economía de corte neoliberal, con privatización de las telecomunicaciones, la energía y la banca, las concesiones de servicios públicos, la reducción de aranceles y la negociación de tratados de "libre" comercio. Los sectores financieros de la exportación no tradicional - por ejemplo, la maquila-, del comercio y el turismo, se han beneficiado a costa de la agricultura y las industrias tradicionales. Estos procesos han generado divisiones entre grupos empresariales, mientras que los principales promotores y beneficiarios de la liberalización se han consolidado en grupos de gran poder económico de dimensión regional. Son una extensión de las oligarquías tradicionales nacionales, ahora con un poder más grande y más concentrado que nunca.

Al mismo tiempo, el nuevo modelo ha favorecido la penetración de empresas transnacionales, socios de esta nueva élite, que pronto quedará subordinada al poder del capital transnacional. Como en otras partes de América Latina, Estados Unidos se está encargando del aparato productivo del istmo. Y con la aprobación, este año, del tratado de libre comercio $(C A F T A-D R)$, sus empresas penetrarán más rápidamente en Centroamérica. La integración de las economías regionales

6. Instituto Universitario de Opinión Pública-UCA, Boletín de prensa, XXI, 2 (28 de mayo de 2006), 13.

7. PNUD CA, p. 41 y Cap. 5, passim. En las próximas dos secciones sigo el análisis de Segovia, op. cir. 
con la de Estados Unidos es profunda, y ha generado dependencias también profundas. En 2001 , un $64.2 \%$ de las exportaciones de la region iba a Estados - Unidos

Las nuevas cúpulas regionales y transnacionales protagonizan una globalización y "regionalización" caótica, sin orientaciones, por parte de autoridades públicas, y en función de ganancias, no del bien común.

La política. Los gobiemos nacionales jugaron un papel decisivo en facilitar las condiciones para el nuevo modelo económico, pero la actividad de las nuevas élites regionales escapa a su control. Junto con las cúpulas económicas nacionales, estos grupos influyen e incluso controlan los gobiernos. Intervienen directamente en los tres poderes del Estado. Los gobiernos son ahora gobiemos empresariales o pro-empresariales, y en su mayoría, autoritarios y con políticas excluyentes.

El Estado casi se ha privatizado. Su debilitamiento ha sido una condición y una consecuencia del nuevo modelo económico. Los partidos políticos, las clases medias, los sindicatos y la pequeña y mediana empresa - que servían de contrapeso al gran capital - pierden su capacidad para incidir, en la vida pública y en la economía. Y este nuevo desequilibrio amenaza el desarrollo humano y la consolidación de la democracia.

Vivimos una democracia light, de baja intensidad, con estados de derecho enfermizos. Falta la transparencia y la capacidad para pedir responsabilidades. Se siguen violando los derechos fundamentales de grupos y personas indefensos?. Los alarmantes niveles de corrupción e impunidad alimentan la violencia social.

Faltan estructuras normativas para las elecciones, especialmente por lo que toca al financiamiento político y el acceso a los medios de comunicación. Los monopolios de estos medios, la intimidación, la autocensura y la falta de acceso a los mismos corroen la cultura política. El gasto público para la democracia, la reforma jurídica y la defensa de los derechos es "extremadamente bajo"10.

El gasto público social es bajo, y más en comparación con el resto de América Latina. Guatemala, El Salvador, Honduras y Nicaragua son los cuatro países centroamericanos con mayor número de pobres, y sin embargo, tienen niveles de gasto social que están entre los más bajos del hemisferio, con in-

8. Programa de Naciones Unidas para el Desarrollo, Informe sobre desarrollo humano, El Salvador 2003. Desafios y opciones en tiempos de globalización (San Salvador, 2003), 155. En adelante, me referire a esta fuente como "PNUD El Salvador".

9. Programa Centroamérica de la Federación Luterana Mundial (en colaboración con ocho organizaciones de derechos humanos), Centroamerica 2004-2005: Desde una perspectiva de derechos humanos. http://www.lwfcamerica.org/contenido.php? $\operatorname{cod}=204$.

10. PNUD CA, p. 37. 
versiones ínfimas en educación, salud, nutrición y seguridad social". Costa Rica y Panamá, que no cuentan con fuerzas armadas, tienen un gasto social más elevado, mientras que los demás países gastan lo que no tienen para mantener ejércitos innecesarios, los que, a la postre, evaden el control civil y democrático. Los sistemas tributarios regresivos, la recaudación muy baja y la amplia evasión de impuestos, también dificultan el gasto social ${ }^{12}$.

Resumiendo, en estos últimos años, la mayor concentración de poder económico y político ha ido de la mano de niveles de pobreza muy altos. Se está promoviendo una mayor desigualdad económica y polarización política, limitando y entorpeciendo la democracia institucional. $Y$ en tres de los países centroamericanos se ha vivido un período de posguerra, sin llegar a una reconciliación nacional. Por ello, aunque estamos lejos de nuevas guerras, sí amenaza la inestabilidad.

Cultura y religión. Los pueblos indígenas constituyen más del $16 \%$ de la población, y en Guatemala más del $40 \%$. Como los afrodescendientes de la Costa atlántica y Panamá, estos pueblos sufren discriminación y pobreza desproporcionada, pero son cada vez más activos en la vida social y política ${ }^{13}$.

En Centroamérica, como en toda América Latina y El Caribe, en las últimas décadas, la Iglesia católica ha sufrido una constante pérdida de miembros. La World Christian Encyclopedia, conocida por su objetividad, estima que el $92.7 \%$ de la población latinoamericana y caribeña se profesa cristiana - con un $\mathbf{8 8 . 8 \%}$ de católicos y un $9.3 \%$ de protestantes ${ }^{14}$. Estas cifras, del año 2000 , parecen subestimar el aumento de la población protestante. Entre 12 y 15 por ciento sería más realista's. El caso de El Salvador ilustra la dinámica de Centroamérica. En 1988 , un $67 \%$ de la población salvadoreña se profesaba católica con un $16.4 \%$ "evangélica" ${ }^{16}$. Actualmente, es decir, dieciocho años más tarde, $56.0 \%$ se decla-

11. El gasto público social en América Latina llega a s6lo el $13.8 \%$ del PIB (dalos de 2000-2001). En Panamá, llega al 25.5\%; en Costa Rica, al 18\%. Para los palses centroamericanos con más pobres -y PIB muy bajo-, los datos espantan: Nicaragua, 13\%; Honduras, $10 \%$; El Salvador, $8 \%$; Guatemala, $6 \%$. El gasto público en salud en Panamá es el 4.8\% del PIB; en Costa Rica, 4.7\%; Honduras, 4.3\%; El Salvador, 3.6\%; Nicaragua y Guatemala, 2.3\%. PNUD El Salvador, pp. 65, 79; cfr. PNUD CA, p. 71.

12. PNUD CA, Pp. 38, 42, 115-116.

13. PNUD CA, pp. $43,63$.

14. David B. Barret, et al., World Christian Encyclopedia: A Comparative Survey of Churches and Religions in the Modern World, 2nd edn. 2 vol. (Oxford University Press, 2001), Vol. 1, p. 14.

15. John Allen, "All Things Catholic", National Catholic Reporter, 5, 49, Aug. 18, 2006, versión en línea.

16. IUDOP-UCA, "La religión para los salvadoreños", San Salvador, 19 de octubre de 1988 , p. 4. Un $14.7 \%$ dijo "no tener confesión religiosa alguna", lo cual no implica necesariamente increencia. 
ran católicos y $28.6 \%$ protestantes ${ }^{17}$. Esta dinámica, que comenzó mucho antes, se manifiesta en toda la región. Aunque las iglesias y sectas pentecostales de hoy - son muy diferentes a las iglesias protestantes históricas, el crecimiento de aquéllas sólo puede compararse con los cambios demográficos de la reforma protestante del siglo XVI.

Muy pronto, y por primera vez en su historia, la mayoría de la población centroamericana vivirá en ciudades. Es una población joven; la mitad tiene 21 años o menos $^{18}$. La juventud de hoy constituye la primera generación expuesta universalmente, desde la niñez, a la televisión y al pluralismo cultural y religioso, con todos los desafíos que ello implica para la vida familiar y la formación humana y cristiana. Muchos jóvenes, ellas y ellos, experimentan períodos de profunda desorientación personal, crisis de sentido y crisis de identidad. Como la mayoría carece de una sólida formación en la fe, los desafíos pastorales son grandes. Por otra parte, la población centroamericana mantiene una gran sensibilidad religiosa. Casi toda la población salvadoreña, típica para Centroamérica, se declara creyente ${ }^{19}$. El $87 \%$ considera que la religión es muy importante en su vida ${ }^{20}$. Ante los cambios socioculturales profundos y con la sensibilidad religiosa que persiste, el futuro de la religiosidad - y la calidad de la fe-es difícil de prever.

Con todas sus ambigüedades, la religiosidad es una de las grandes riquezas de Centroamérica. ¡No todo es tinieblas en la región, ni mucho menos! Como se dijo al comienzo, somos países de extremos - de pecado cruel y gracia abundante, de cruces y resurrecciones, a la vez. Es alentador notar, por ejemplo, cómo la solidaridad internacional crece y madura como fuerza positiva frente a las injusticias que cada vez más se presentan con una dimensión internacional. Pero sobre todo, entre los y las pobres, contamos con una reserva profunda de humanidad y de fe cristiana. Quienes más sufren, celebran el don de la vida con profunda gratitud; comparten lo poco que tienen. Practican la hospitalidad, resisten tercamente los atropellos en su contra, construyen la Iglesia y con generosidad, se ponen a su servicio, contagian su fe, su esperanza y el amor solidario. Sobre esta base, la Iglesia tiene que construir su futuro.

Nos preguntamos ahora, ¿qué dice la fe cristiana ante esta realidad de sombras y luces?

17. IUDOP-UCA, Boletín de prensa, XXI, n. 1, 2006, p. 22 . Un $12.9 \%$ decía no pertenecer a ninguna religión.

18. Extrapolación de United Nations Department of Economic and Social Affairs, Population Division, "National Trends in Population, Resources, Environment and Development: Country Profiles", http://www.un.org/esa/population/publications/ countryprofile/profile.htm, consultado el 10 de septiembre de 2006.

19. En 1995, s6́lo 1.1\% dijo no creer en Dios. IUDOP-UCA, "La religión de los salvadoreños en 1995", Estudios Centroamericanos 563 (1995) 853.

20. IUDOP-UCA, Encuesta sobre valores, Serie de Informes 80 (1999), p. 14. 


\section{Juzgar}

No pretendemos interpretar y evaluar la realidad descrita, sino, más modestamente, indicar y proponer los criterios que consideramos centrales para realizar ese "juicio", a la luz de la fe.

Según el documento preparatorio de Aparecida, los obispos propondrán, como idea central, que se intensifique la evangelización como misión de la Iglesia. Esta es la misión que el mismo Jesús dio a sus discípulos, y la que les sigue dando. La Iglesia universal ha insistido en esta prioridad, desde el sínodo en Roma sobre la evangelización (1974), la Evangelii nuntiandi de Pablo VI (1975) y la "nueva evangelización", promovida desde hace más de veinte años, por Juan Pablo II. Ciertamente, parece una estrategia pastoral atinada.

Por otra parte, llama la atención que en el período posconciliar - en cuanto yo conozco-, ningún documento oficial jerárquico explica clara y concisamente el contenido de la evangelización, las buenas noticias - la "salvación"- que hoy se debe anunciar. "Y si la trompeta da un sonido confuso, ¿quién se preparará para la batalla?" (1Cor 14, 8).

La encíclica de Juan Pablo II, Redemptoris missio de 1990, puede ser una excepción. Remonta la evangelización al anuncio y servicio al reino, que Jesús llevó a cabo, y enumera sus elementos fundamentales. Sin embargo, Jesús como primer evangelizador y el reino que anunció no tienen un lugar central en el documento preparatorio de Aparecida. Por eso, hay que recordar lo que dice la Redemptoris Missio. :

Jesús de Nazaret [...] recorte Galilea proclamando la Buena Nueva de Dios: "El tiempo se ha cumplido y el Reino está cerca; conviértanse y crean en la Buena Nueva". [...] La proclamación y la instauración del Reino de Dios son el objeto de su misión [...].

El Reino que inaugura Jesús es el Reino de Dios, [...] al que llama con el término familiar "Abba", [y que] es sensible a las necesidades [...] un Padre amoroso y lleno de compasión" ( $R M 13)$.

La buena noticia de Jesús es el reino de un Dios misericordioso, que se manifiesta en su Hijo, que encarna en persona la Buena Nueva.

Los destinatarios del reino son los pobres y marginados, a quienes Jesús se acerca "dándoles su preferencia". Pues "ha sido enviado a anunciar a los pobres la Buena Nueva" (LC 4, 18). A todas las víctimas de rechazo y desprecio Jesús les dice: "Bienaventurados los pobres" $(L \subset 6,20)$. Además, hace vivir ya a estos marginados una experiencia de liberación, tratándoles como a iguales y amigos (RM 14).

El reino que Jesús anuncia es liberación de la persona entera. Por ello, las curaciones son signo de salvación corporal y también espiritual, de liberación del pecado. En el reino, ya no habrá enfermedades, ni sufrimientos ( $R M 14)$. 
El reino tampoco se limita al individuo, sino que transforma la realidad social, el mundo entero.

El Reino tiende a transformar las relaciones humanas y se realiza progresivamente, a medida que los hombres aprenden a amarse, a perdonarse y a servirse mutuamente [...] La naturaleza del Reino es la comunión de todos los seres humanos entre sí y con Dios [...] Trabajar por el Reino quiere decir reconocer y favorecer el dinamismo divino, que está presente en la historia humana y la transforma. Construir el Reino significa trabajar por la liberación del mal en todas sus formas ( $R M 15$ ).

El reino es, pues, liberación integral. Ya lo había afirmado Puebla, y ya antes, desde Medellín, también la teología de la liberación, sobre la cual Juan Pablo II llegó a escribir en su carta a los obispos de Brasil, en 1986, que "la teología de la liberación es no solamente oportuna sino útil y necesaria", lo cual sigue siendo válido hasta el día de hoy.

Predicar el reino y a Jesús, muerto y resucitado, fue desde el principio, la misión de la Iglesia ( $R M$ 16). La Iglesia sigue estando al "servicio del Reino [...] ante todo, mediante el anuncio que llama a la conversion [...] Sirve al Reino, fundando comunidades e instituyendo Iglesias particulares, llevándolas a la madurez de la fe y de la caridad con el servicio a la persona y a la sociedad [...], difundiendo en el mundo los 'valores evangélicos', que son expresión de ese Reino" ( $R M$ 20).

A las comunidades de discípulos -y a la Iglesia entera - les toca ser portadoras de las buenas noticias del reino: la presencia activa de Dios para liberar a la humanidad (y a toda la creación) de todas sus cadenas, y sobre todo del pecado. Dios ofrece perdon y llama a la conversión. Siguiendo al maestro, sus discípulos se solidarizan con pobres y marginadas, dando testimonio de que Dios trae fraternidad y vida eterna. Las comunidades de discípulos ya encarnan esta vida nueva, que ha de triunfar sobre el pecado, la persecución y la muerte. Son sacramento de salvación, vanguardia del reino en el mundo.

Aunque hay que concretar e historizar la Redemptoris missio, pocos documentos bosquejan el evangelio con tanta claridad. Así perfiladas, las buenas noticias responden, aunque sea en términos muy generales, a las malas noticias que nos rodean. Pero debemos preguntarnos si en nuestras iglesias y parroquias, si en la predicación, la teología y la catequesis, proclamamos este evangelio.

¿Cuánto eco hay de esta encíclica, en los documentos y la pastoral de nuestras iglesias nacionales? ¿Y en Centroamérica? Demasiado poco. Por otra parte, se vive este mensaje en muchas comunidades que se han inspirado y animado por la herencia eclesial, recibida en varios países, y notablemente, en Centroamérica. 
Las cartas pastorales de Monseñor Romero, por mencionar el ejemplo más insigne, siguen iluminando lo que debe ser la evangelización hoy, añadiendo a los temas ya citados la pastoral de acompañamiento a los cristianos comprometidos. Sus homilías siguen siendo ejemplo insigne de profecía y de consolación a los pobres y oprimidos. Su trabajo por construir un cuerpo eclesial, más allá de una comunión de solas palabras, sigue animando a que las comunidades caminen como pueblo de Dios, abiertas a todas las iglesias cristianas, y a todos los hombres y mujeres de buena voluntad. Su entrega total a los pobres y su aceptación agradecida de la salvación, que viene de los pobres, se nos sigue ofreciendo como el fundamento de una Iglesia de los pobres, en el mundo de hoy.

En los países centroamericanos es de especial importancia la herencia martirial. Desde el asesinato del padre Héctor Gallego, el 9 de junio de 1971, en Panamá, decenas de sacerdotes, religiosos y religiosas, han sido asesinados. Y junto con ellos, muchos otros agentes de pastoral y misioneros laicos, delegados y celebradores de la Palabra, catequistas, sacristanes, trabajadores sociales y de derechos humanos, muchos hermanos y hermanas protestantes, pastores y ministros, diáconos y predicadores, innumerables campesinos, indígenas, obreros, estudiantes, maestros, periodistas, enfermeras, médicos, profesores e intelectuales. Es el testimonio, en grado insigne, que, según la Evangelii nuntiandi, es elemento esencial de la evangelizacion.

El martirio de Monseñor Romero, en 1980, tiene un potencial evangelizador inigualable. Junto a él, también el martirio de Monseñor Juan Gerardi, en Guatemala, en 1998, y el de Monseñor Joaquín Ramos, en El Salvador, en 1993. La verdad, la compasión, la justicia y la entrega, por amor, de estos mártires, ofrecen una poderosa luz para juzgar nuestro mundo y nuestra Iglesia. Y ofrecen también luz y ánimo para encontrar el camino concreto de una evangelización adecuada, en nuestros días.

También hay que tener presente la teología que se ha desarrollado en estos países sobre liberación y evangelización, misión y testimonio, fe y martirio, seguimiento de Jesús y misterio de Dios. Por sus raíces concretas en el Jesús de los evangelios y por su apertura al Espíritu de Dios, esta tradición teológica puede ofrecer luz sobre el pasado y el futuro. Por lo que toca a la temática de la V Conferencia, pueden verse, por ejemplo, las reflexiones que se han publicado en El Salvador sobre Jesús, reino de Dios y misión evangelizadora ${ }^{21}$.

21. Ver, por ejemplo, los siguientes artículos, en Revista Latinoamericana de Teologia 68 (2006); Jon Sobrino, "El reino de Dios anunciado por Jesús fundamental para la vida cristiana", 135-160; Pedro Trigo, "La mision en la Iglesia latinoamericana actual", 161-194; Xavier Alegre, "La paz en el evangelio", 195-215; y mi libro Divine Revolution: Salvation and Liberation in Catholic Thought, Maryknoll, N.Y., 1996 (reimpresión, Eugene, Ore., 2004). 
Queda ahora la pregunta. A la luz del evangelio, ¿cómo debemos responder como Iglesia, a nuestra cruda realidad?

\section{Actuar}

Con las sugerencias que ahora proponemos no se pretende decirlo todo, ni siquiera todo lo importante, ni aún lo necesario. Nos interesa sobre todo reflexionar sobre cómo la Iglesia puede responder al dolor y las injusticias, que abaten a las mayorías centroamericanas, así como a las del resto del continente. Ante esta realidad masiva, la pregunta central para la Iglesia es, ¿como llevar buenas noticias a los pobres - y así, a todos y todas?

La evangelización. Los obispos piensan proponer en Aparecida una misión de evangelización, en todo el continente. De ello hay gran necesidad, y puede ser muy oportuna, si se lleva a cabo adecuadamente. La cultura de consumo ha dejado a la gente hambrienta de verdad y de sentido. Como nunca antes, las poblaciones son bombardeadas por muchas ofertas, seculares y religiosas, poco dignas e incluso destructivas. Se presenta una gama de modelos a imitar, desde Madre Teresa y Alberto Hurtado a Shakira y los galanes de telenovelas, y cosas peores. Poco deben sorprender los altos niveles de desorientación.

En medio de la confusión de voces e imágenes, existen oportunidades, pues. Gracias a Dios, los pueblos latinoamericanos y caribeños mantienen una marcada sensibilidad hacia lo trascendente. Pero, por otra parte, les falta formación, y caen con facilidad en los fundamentalismos. La gran mayoría cree en Dios, sí; pero ¿en qué Dios creen? Y ¿estará la Iglesia a la altura de su hambre de verdad del Dios de Jesús?

Hay hambre de espíritu, no cabe duda. Pero tampoco hay duda de la profunda crisis de credibilidad, que amenaza a las instituciones y autoridades tradicionales, incluso a la Iglesia. En un mundo cada vez más pluralista, de cultura crítica y con mucho cinismo - donde los medios de comunicación ya no perdonan-, la credibilidad se gana, únicamente, a través de la autenticidad y del testimonio coherente. Ahora más que nunca, como lo dijo el mártir Luis Espinal de Bolivia, "una religión que no tenga la valentía de hablar en favor del hombre, tampoco tiene el derecho a hablar en favor de Dios"22. Una Iglesia que no camina con las víctimas, con todas las consecuencias que eso trae, no será creíble. En adelante, sólo será creible un amor solidario y fiel, dispuesto a pagar el precio.

El que la Iglesia pierda miembros presenta un gran desafío, ciertamente, pero la única respuesta digna es ser fiel a su Señor. Una Iglesia que se dedica principalmente a salvar su vida, la perderá. Pero si la pierde, en servicio de los Cristos crucificados del continente, la encontrará.

22. Luis Espinal, "Religion", en Oraciones a quemarropa, Sucre, 1981, p. 83. 
Ante las enormes injusticias, la Iglesia tiene que acompañar a las víctimas pobres, renovando su propia vocación profética - en defensa de la vida, promoviendo la reconciliación y el auténtico bien común.

La vida. El reino de Dios es vida en plenitud. Nadie duda del compromiso de la Iglesia católica, en pro de la vida antes de nacer, ni de su esperanza de vida después de morir. Y así debe ser. El gran desafío es defender la vida, después de nacer y antes de morir. Y es la condición de credibilidad para quienes hablan de vida eterna. Esta defensa, lo sabemos, trae persecución. Lleva a la cruz.

La Iglesia debe seguir defendiendo la familia, cuyo mayor peligro no viene de matrimonios homosexuales, sino de la pobreza, del desempleo y de la necesidad de emigrar de madres y padres, para alimentar a sus hijos. Para fortalecer la familia, hay que promover una remuneración adecuada, para el trabajo, y defender los demás derechos laborales.

Se le acusa a la Iglesia de asumir posturas irresponsables ante el crecimiento demográfico - problema real, en algunos países como El Salvador. Y de esto se debe hablar en serio. Pero hay que aprovechar la oportunidad que las críticas presentan, y responder con una propuesta positiva, basada en la realidad. Los mejores estudios confirman que la estrategia más eficaz para bajar las altas tasas de natalidad es la de promover a la mujer pobre, brindándole oportunidades para la educación, el empleo digno y la participación social.

Conversión y reconciliación. Hay que llamar a todos a la conversión; pero en el continente más cristiano y más desigual, hay que llamar, en particular a los ricos y poderosos, a la conversión y a reconciliarse con los pobres. ¿Se puede ser un continente de esperanza y no hacerlo?

El bien común. En nuestra América Latina, en lugar del bien común prevalece lo que Ignacio Ellacuría llamó el mal común. Ante esta realidad, hay que promover una formación amplia en la doctrina social católica. A la Iglesia, sobre todo, le toca la proclamación profética, basada en esa doctrina, y un mayor empeño en corregir los abusos frecuentes de sus principios. Los principios más fundamentales de esa enseñanza son la dignidad de la persona y el bien común. Todo gira en torno a ellos.

Los gobiernos centroamericanos -y la mayoría del hemisferio - han abandonado la tarea que les compete de ser garantes del bien común, convirtiéndose en instrumentos de los grupos más privilegiados. Se privatizan las industrias públicas estratégicas, aunque, en realidad, sólo se privatizan las más rentables, las que prometen beneficios abundantes a quienes las compran. Es distorsión de la realidad y mala fe defender estas políticas, en base al principio de subsidiaridad, pues éste es un criterio al servicio del bien común. El principio de subsidiaridad especifica cómo debe realizarse el bien común, es decir, en forma participativa y democrática, sin totalitarismos. 
El bien común pasa por la defensa de los grupos más vulnerables. Esta defensa requiere que se paguen los impuestos; exige reformas tributarias y niveles de gasto social, que permitan una vida digna para cada familia.

Es hora de retomar lo que se afirmó en Medellín, "el sistema empresarial latinoamericano y, por él, la economía actual, responden a una concepción errónea sobre el derecho de propiedad de los medios de producción y sobre la finalidad de la economía". El "sistema liberal capitalista [y el] sistema marxista [...] atentan contra la dignidad de la persona humana" (Medellín, "Justicia", 10). Hay que promover una economía más participativa y solidaria, con diversas formas de propiedad (Santo Domingo, 201), que permita superar las desigualdades escandalosas y consolidar democracias participativas y estados de derecho, que defiendan los derechos fundamentales. Esto requiere un marco jurldico adecuado, ausente hoy, para regular el mercado.

Finalmente, veamos los sueños. Sueño con que esta V Conferencia anime a los y las discípulos de Cristo a construir una cultura de paz, en medio de tanta violencia: formar a la gente en modos pacíficos de manejar conflictos, llamar a las autoridades a transformar sistemas penales vengativos, en sistemas de rehabilitación y restauración social. Sueño, incluso, con que la Iglesia pida que las fuerzas amadas de América Latina y El Caribe sé reduzcan gradualmente hasta eliminarsé. La experiencia de Costa Rica y Panamá demuestra que eso es posible y deseable. Libera recursos para el gasto social y favorece el tipo de desarrollo social, que constituye la seguridad nacional real.

La Iglesia. Se suele insistir en el bien común dentro de la Iglesia, y, en años recientes, se apela al principio de subsidiaridad, en la sociedad, es decir, al exterior de la Iglesia. ¿No sería mejor invertir estas prioridades, recalcando el bien común de la sociedad y la subsidiaridad en la Iglesia, comenzando por la misma V Conferencia?

Sueño con una Conferencia que manifieste aquella comunión y participación que la Iglesia anuncia al mundo como buena noticia. En el proceso preparatorio, hay que recoger, escuchar y ponderar los insumos de las iglesias nacionales, del pueblo creyente, sobre todo de quienes tienen menos voz y con frecuencia sirven más a la misma Iglesia: pobres, mujeres, minorías étnicas. Estos grupos deben tener presencia en la Conferencia. También deben tener participación adecuada los representantes de otras iglesias cristianas. Hoy día, y en adelante, escuchar atentamente a todas estas voces y aprender de ellas, lejos de minar la autoridad de la Iglesia, más bien la fortalece y le otorga credibilidad.

Sueño con una Conferencia que manifieste no sólo lealtad al magisterio universal, sino también una fe profunda en el Espíritu Santo, presente en las iglesias locales. Que se eviten dependencias excesivas, y tantas referencias a textos y 
autoridades, que hace dudar de esa fe. Que se hable con voz propia, de América Latina y El Caribe.

Finalmente, en sus labores y su escrito final, que esta V Conferencia retome el método ver-juzgar-actuar, que fue tan fructífero en la Gaudium et spes, en Medellín y en Puebla.

Aunque abunda el pecado en el hemisferio, sobreabunda la gracia de tantas y tantos fieles con vocación de amar y servir. Tenemos el derecho de soñar y el deber de pedir que el Espíritu se sirva de esta asamblea, para hacer de la Iglesia una luz más clara de la esperanza, un instrumento más eficaz de vida plena. 